\title{
Real-Time Strategy Video Game Experience and Visual Perceptual Learning
}

\author{
마ong-Hwan Kim, ${ }^{1}$ @Dong-Wha Kang, ${ }^{1}$ Dongho Kim, ${ }^{2}$ Hye-Jin Kim, ${ }^{1}$ Yuka Sasaki, ${ }^{2}$ and Takeo Watanabe ${ }^{2}$ \\ ${ }^{1}$ Department of Neurology, Asan Medical Center, University of Ulsan College of Medicine, Songpa-gu, Seoul 138-736, South Korea, and ${ }^{2}$ Department of \\ Cognitive, Linguistic, and Psychological Sciences, Brown University, Providence, Rhode Island 02912
}

Visual perceptual learning (VPL) is defined as long-term improvement in performance on a visual-perception task after visual experiences or training. Early studies have found that VPL is highly specific for the trained feature and location, suggesting that VPL is associated with changes in the early visual cortex. However, the generality of visual skills enhancement attributable to action video-game experience suggests that VPL can result from improvement in higher cognitive skills. If so, experience in real-time strategy (RTS) video-game play, which may heavily involve cognitive skills, may also facilitate VPL. To test this hypothesis, we compared VPL between RTS video-game players (VGPs) and non-VGPs (NVGPs) and elucidated underlying structural and functional neural mechanisms. Healthy young human subjects underwent six training sessions on a texture discrimination task. Diffusion-tensor and functional magnetic resonance imaging were performed before and after training. VGPs performed better than NVGPs in the early phase of training. White-matter connectivity between the right external capsule and visual cortex and neuronal activity in the right inferior frontal gyrus (IFG) and anterior cingulate cortex (ACC) were greater in VGPs than NVGPs and were significantly correlated with RTS video-game experience. In both VGPs and NVGPs, there was task-related neuronal activity in the right IFG, ACC, and striatum, which was strengthened after training. These results indicate that RTS video-game experience, associated with changes in higher-order cognitive functions and connectivity between visual and cognitive areas, facilitates VPL in early phases of training. The results support the hypothesis that VPL can occur without involvement of only visual areas.

Key words: diffusion-tensor imaging; functional magnetic resonance imaging; probabilistic tractography; texture discrimination task; video game experience; visual perceptual learning

Significance Statement

Although early studies found that visual perceptual learning (VPL) is associated with involvement of the visual cortex, generality of visual skills enhancement by action video-game experience suggests that higher-order cognition may be involved in VPL. If so, real-time strategy (RTS) video-game experience may facilitate VPL as a result of heavy involvement of cognitive skills. Here, we compared VPL between RTS video-game players (VGPs) and non-VGPs (NVGPs) and investigated the underlying neural mechanisms. VGPs showed better performance in the early phase of training on the texture discrimination task and greater level of neuronal activity in cognitive areas and structural connectivity between visual and cognitive areas than NVGPs. These results support the hypothesis that VPL can occur beyond the visual cortex.

\section{Introduction}

Visual perceptual learning (VPL) is defined as experience- or training-dependent performance improvements on a visual task

Received Aug. 5, 2014; revised June 13, 2015; accepted June 15, 2015.

Author contributions: Y.-H.K., D.-W.K., D.K., H.-J.K., Y.S., and T.W. designed research;Y.-H.K., D.-W.K., D.K., and H.-J.K. performed research; Y.-H.K., D.-W.K., and D.K. analyzed data; Y.-H.K., D.-W.K., D.K., H.-J.K., Y.S., and T.W. wrote the paper.

This study was supported by National Research Foundation of Korea Grants 2011-0016868 and NRF2014R1A2A1A11051280 funded by the Korean government, the Korea Health Technology R\&D Project, Ministry for Healthcare and Welfare, Republic of Korea Grants HI12C1847 and HI14C1983, Asan Institute for Life Sciences Grant 2014-625, NIH Grants NIH-EY-019466 (to T.W.) and NIH-MH-091801 (to Y.S.).

The authors declare no competing financial interests. and is regarded as a manifestation of adult plasticity (Karni and Sagi, 1991; Yotsumoto et al., 2008; Sasaki et al., 2010; Beste and Dinse, 2013). VPL has attracted attention because of its benefits for visual perceptual ability, and there have been continuous endeavors to use VPL in clinical settings, such as to treat amblyopia (Hussain et al., 2012; Xi et al., 2014; Zhang et al., 2014), presbyopia (Polat, 2009), and stroke (Huxlin et al., 2009), and sports settings to enhance sports performance (Deveau et al., 2014).

Correspondence should be addressed to Dong-Wha Kang, 88 Olympic-ro 43-gil, Songpa-gu, Seoul 138-736, South Korea. E-mail: dwkang@amc.seoul.kr.

DOI:10.1523/JNEUROSCI.3340-14.2015

Copyright $\odot 2015$ the authors $\quad 0270-6474 / 15 / 3510485-08 \$ 15.00 / 0$ 
Many types of VPL have been found to be highly specific for the trained feature and location. Such specificity has led researchers to suggest that VPL is associated only with changes in the early visual cortex in which visual information is processed in a more specific manner than in higher visual and cognitive areas (Poggio et al., 1992; Karni and Sagi, 1993; Crist et al., 1997; Watanabe et al., 2002). This view was supported by a number of physiological evidence (Schoups et al., 2001; Furmanski et al., 2004; Yotsumoto et al., 2008, 2009; Shibata et al., 2011).

However, it has been found that action video-game experience improved visual performance in much more general ways than has been found in traditional VPL studies (Green and Bavelier, 2003, 2012; Green et al., 2010; Oei and Patterson, 2013; Wu and Spence, 2013). These results suggest that video-game playing enhances attentional control (Cardoso-Leite and Bavelier, 2014), the ability to learn new tasks (Green and Bavelier, 2012), and reweighting the connectivity between visual areas (Bejjanki et al., 2014), which may mainly occur as a result of involvement in higher areas than the early visual cortex and that the improvement of such abilities also leads to VPL. Recently, it has been suggested that VPL results from improvement in a feature representation in the early visual cortex or in task strategies in higherorder cognitive areas (Watanabe et al., 2002; Harris et al., 2012; Shibata et al., 2014; Watanabe and Sasaki, 2015). In this view, either improvement in the early visual cortex or higher regions is sufficient for VPL to occur.

Here we aimed to test whether high-order cognitive skills are involved in VPL by testing whether real-time strategy (RTS) video-game experience facilitates VPL. Previous studies have found that action video games improve certain executive and cognitive tasks (Green et al., 2012; Strobach et al., 2012) and visual tasks in association with reweighting connectivity between visual areas (Bejjanki et al., 2014). RTS video games may particularly rely heavily on high-order cognitive strategies that require flexible allocation and integration of different cognitive skills (Basak et al., 2008, 2011; Glass et al., 2013; Dobrowolski et al., 2015). Recent research supports this view. The gray-matter volumes of the medical prefrontal cortex, cerebellum, postcentral gyrus, anterior cingulate cortex (ACC), and dorsolateral prefrontal cortex were correlated with improvement in an RTS video game (Basak et al., 2011). Thus, if RTS video-game players (VGPs) have stronger structural and/or functional mechanisms in high-ordered cognitive areas and show a greater ability to develop VPL than non- (or less-experienced) VGPs (NVGPs), this will support the hypothesis that VPL is associated with changes in these higher-order cognitive areas.

With these considerations in mind, we sought to compare VPL between RTS VGPs and NVGPs and to elucidate the structural and functional neural mechanisms that underlie the interindividual differences in VPL using diffusion-tensor imaging (DTI) and functional magnetic resonance imaging (fMRI).

\section{Materials and Methods}

Subjects and experimental design. Subjects were 31 males aged 22-36 years. All subjects completed a structured, written questionnaire and interview on demographics, education and socioeconomic status, and video-game playing experience. Inclusion criteria for VGPs were as follows: (1) experience (>1000 plays) of RTS game play, e.g., StarCraft and WarCraft; and (2) played RTS games at least $3 \mathrm{~d}$ /week for a minimum of $1 \mathrm{~h} / \mathrm{d}$ for the previous 3 months. Inclusion criteria for NVGPs were as follows: (1) no or little previous experience of video-game play; and (2) had not played any type of game for $>10$ h over the past year. All subjects provided written informed consent to participate in the experiment, and the protocol was approved by the Institutional Review Boards of the Asan Medical Center.

Texture discrimination task training. The texture discrimination task (TDT) was used to elicit and assess VPL (Karni and Sagi, 1991). Visual stimuli were presented on an LCD screen at a viewing distance of $57 \mathrm{~cm}$. A test stimulus was presented very briefly ( $17 \mathrm{~ms}$ ) and was followed by a variable-duration blank screen and then a mask stimulus (100 ms). The target screen consisted of a centrally located fixation letter (randomly rotated $\mathrm{L}$ or $\mathrm{T}$ ) and a peripherally positioned texture target array (a horizontal or vertical array of three diagonal bars, ü on a background of horizontal bars (-). While keeping their eyes fixated on the center of the stimulus display, subjects were asked to respond twice for each trial: once to identify the letter ( $\mathrm{L}$ or $\mathrm{T}$ ) and once to indicate the orientation (horizontal or vertical) of the target array by pressing two of four buttons on a response button box. The purpose of the letter task was to ensure that the subject's gaze was fixed on the center of the display. In each trial, fixation, blank, target, blank, mask, fixation, and response screens were presented sequentially in their respective order. Auditory feedback was provided immediately after a subject's response to the fixation letter. No feedback was given for a texture target array response (Karni and Sagi, 1991; Sagi and Tanne, 1994). Correct response for a texture target array was counted only if the response to a fixation letter was correct.

Each subject completed six training sessions over a period of 2 weeks. During the training sessions, the horizontal or vertical target array was presented only in one quadrant of the visual field. This quadrant, i.e., the trained visual field, was counterbalanced across the subjects and groups and was the upper right quadrant for 14 subjects $(n=7$ for VGPs and $n=$ 7 for NVGPs) and the upper left quadrant for 17 subjects ( $n=9$ for VGPs and $n=8$ for NVGPs).

The time interval between the onsets of the target and the mask screen was defined as the stimulus-to-mask onset asynchrony (SOA). Seven different SOAs were used in each training session. The SOAs used were selected from eight possible SOAs $(550,300,250,200,150,120,100$, and $80 \mathrm{~ms}$ ). Each training session contained 21 blocks of trials. The SOA was constant within each block and was constant for three consecutive blocks, corresponding to 120 consecutive trials for sessions 1 and 2 (40 trials in each block) and 80 consecutive trials for sessions 3-6 (27 trials in the first and second blocks and 26 in the third block of the same SOA). This resulted in a total of 840 trials in sessions 1 and 2 and 560 trials in sessions 3-6.

The initial SOA in the first training session was $550 \mathrm{~ms}$, and then SOAs became progressively shorter (i.e., 300, 250, 200, 150, 120, and $100 \mathrm{~ms}$ ). To induce maximum perceptual capability and to avoid subjects from being bored of performing the task, the initial SOA from the second to the last training sessions was adjusted as follows: the initial SOA was 300 $\mathrm{ms}$ if performance was $>80 \%$ for the $150 \mathrm{~ms} \mathrm{SOA}$ in the previous training session and was $550 \mathrm{~ms}$ if performance was $\leq 80 \%$ for the $150 \mathrm{~ms} \mathrm{SOA}$ in the previous training session. For each subject, a logistic function was fitted to the rate for the training session to construct a psychometric curve, and the SOA corresponding to $80 \%$ performance accuracy was taken as a threshold measure for the training session.

TDT during fMRI. Subjects performed the TDT in an fMRI session before and after training. In the fMRI session before training, subjects performed at least 32 practice trials to ensure that they understood the task. During fMRI sessions, TDT stimuli were presented via visual goggles (NordicNeuroLab). The texture target arrays were displayed in either the upper left visual field or the upper right visual field (i.e., the trained or untrained visual field from the training session) using an event-related fMRI paradigm. The display position of the text target array was randomized. The timing for the presentation of each trial was calculated with optseq2 software (Dale, 1999; Dale et al., 1999) to randomize the interstimulus interval from trial to trial to maximize the statistical efficiency. Each fMRI session contained 224 TDT trials $(n=$ 112 trials for each of the two visual fields). Trials were conducted over seven runs, i.e., 32 trials per run. At the beginning of each trial, a blue or green fixation cross was presented for $500 \mathrm{~ms}$, followed by a blank screen for $250 \mathrm{~ms}$. The color of the fixation cross served as a cue for the location of a texture target array to follow. A blue fixation cross indicated that the texture target array would appear at the trained visual field (quadrant); a 
green cross indicated that the array would appear at the untrained visual field (quadrant). A target screen was then presented for $20 \mathrm{~ms}$, followed by a mask screen for $100 \mathrm{~ms}$. The SOA between the target and mask screen was constant at $100 \mathrm{~ms}$ for 17 subjects (Experiment $1 ; n=9$ for VGPs and $n=8$ for NVGPs) and $150 \mathrm{~ms}$ for 14 subjects (Experiment 2; $n=7$ for VGPs and $n=7$ for NVGPs). As in the behavioral training session, subjects were asked to respond to the fixation and texture targets by pressing a button on a box that they held in their right hand. Immediate auditory feedback was given only for the fixation letter task (Karni and Sagi, 1991; Sagi and Tanne, 1994; Yotsumoto et al., 2008). Task performance during fMRI was defined as the correct response ratio regardless of two visual field conditions (= the number of correct responses for both fixation and texture target/the number of correct response for fixation target).

The SOA in Experiment $1(100 \mathrm{~ms})$ was selected a priori based on a previous study (Yotsumoto et al., 2008). However, no improvement in performance was observed from before to after training, although subjects had a threshold SOA of $127 \pm 37 \mathrm{~ms}$ at the end of the six training sessions. We believe that, in our experimental setting, subjects found it difficult to perceive the texture target with an SOA of $100 \mathrm{~ms}$ when they were in the fMRI environment. Thus, the constant SOA was changed to $150 \mathrm{~ms}$ for Experiment 2, and the correct response ratio increased from before to after training. For this reason, neuronal activities during the task were investigated on only the fMRI data collected in Experiment 2.

Image acquisition and preprocessing. Subjects were scanned in a $3 \mathrm{~T} \mathrm{MR}$ scanner (Tim Trio; Siemens). fMRI and DTI scans were obtained in both the pretraining and posttraining sessions, and a high-resolution T1weighted image was acquired in the pretraining session. fMRI was acquired using gradient-echo echo planar imaging sequences (repetition time, $2000 \mathrm{~ms}$; echo time, $30 \mathrm{~ms}$; flip angle, $90^{\circ}$ ) for measurement of blood oxygen level-dependent (BOLD) signal contrast. Thirty-seven slices $(3.125 \times 3.125 \times 3.5 \mathrm{~mm})$ for task scans with interleaved slice sequences were acquired oriented parallel to the anterior commissureposterior commissure plane. In addition, each subject underwent an 11 min echo planer DTI scan (repetition time, $5100 \mathrm{~ms}$; echo time, $88 \mathrm{~ms}$; voxel size, $1.875 \times 1.875 \times 4 \mathrm{~mm})$. Thirty-seven slices were acquired with $b$ values of 0 and $1000 \mathrm{~mm}^{2} / \mathrm{s}$ obtained by applying gradients along 64 different diffusion directions. High-resolution T1-weighted images (MPRAGE; repetition time, $1900 \mathrm{~ms}$; inversion time, $900 \mathrm{~ms}$; echo time, $2.2 \mathrm{~ms}$; flip angle, $9^{\circ}$; 176 slices in the sagittal plane; voxel size, $1 \times 0.5 \times$ $0.5 \mathrm{~mm}$ ) were also acquired.

Acquired high-resolution T1-weighted images were resampled to isotropic $1 \mathrm{~mm}$ voxel size via FreeSurfer (Fischl et al., 2004), which was used to estimate the transformation parameter in the spatial normalization step between the individual high-resolution T1-weighted image and the standard Montreal Neurological Institute (MNI) T1-weighted image. Affine linear and deformable nonlinear registration transform parameters were estimated by using the FMRIB (Functional MRI of the Brain) linear registration tool (FLIRT) and nonlinear registration tool (FNIRT) in the FMRIB Software Library (FSL) (Jenkinson et al., 2012), respectively. Results of segmented regional labels from FreeSurfer (Desikan et al., 2006) were used to define the region of interest (ROI) mask for the visual cortex for each individual.

Preprocessing for echo planar imaging scans was performed using FSL with the following steps: slice timing correction, motion correction, spatial normalization to standard MNI space through the high-resolution T1 image resampled to isotropic $2 \mathrm{~mm}$ voxel size, and spatial smoothing with $8 \mathrm{~mm}$ full-width at half-maximum Gaussian kernel. Diffusionweighted images were corrected for motion and eddy current distortion using the FSL diffusion toolkit (Behrens et al., 2007).

Neuronal activity during the TDT. An event-related BOLD response model (Friston et al., 1998) was used to estimate neuronal activation associated with visual perceptual processing induced by the TDT. In each run, a general linear model was conducted to estimate voxelwise $\beta$ coefficients for the two visual-field conditions: trained (texture target array presented in the trained quadrant) and untrained (texture target array presented in the untrained quadrant) conditions. With consideration of mixing effects of button press in visual perceptual processing, response timings were additionally included in the design matrix. The onset tim- ing of a texture target and response timing were convolved using the canonical hemodynamic response function. To minimize motionrelated effects from the general linear model step for each run, motionrelated regressors, including six rigid-body motion parameters and motion outlier frames (implemented in FSL with the "fsl_motion_outliers" module), were included in the design matrix (Power et al., 2012). An average neuronal activity map was calculated by averaging across seven runs and visual-field conditions and then was used to represent the taskinduced neuronal activity for each subject, for each fMRI session.

A cluster-based correction scheme was adopted to find meaningful differences in neuronal activity between groups or sessions using $\mathrm{Al}$ phaSim (Song et al., 2011). Voxelwise significance was determined at $p<$ 0.001 . Subsequently, cluster-based significance was determined at $p<$ 0.05 (including $>340$ contiguous significant voxels; smoothness estimated as 16.6, 17.6, and $17.0 \mathrm{~mm}$ of full-width at half maximum Gaussian filter for the $x, y$, and $z$ directions, respectively).

Probabilistic tractography. Probabilistic tractography was performed using the FMRIB diffusion toolbox. BEDPOSTX and PROBTRACKX was used to model 5000 iterations within each voxel with a curvature threshold of 0.2 , a step length of $0.5 \mathrm{~mm}$, and a maximum number of 2000 steps (Behrens et al., 2003). The connectivity strength of white matter in the whole brain was reconstructed using an ROI mask in the visual cortex. Visual cortical regions for the ROI mask were prepared based on segmented regional anatomy from FreeSurfer. Segmented regional anatomy was transformed into diffusion space. Regions of pericalcarine, lingual, cuneus, and lateral occipital cortex were included for the visual cortex ROI with $>0.2$ in a fractional anisotropy map. The result of the connectivity strength distribution map was transformed into standard space. For statistical analysis, the connectivity strength map in each subject was normalized to the probabilistic connectivity map (range, 0 to 1 ; divided by the maximum connectivity strength in the distribution map). Voxelwise comparisons were performed to investigate group differences in probabilistic tracts. A cluster-based correction scheme was adopted to find meaningful differences in probabilistic tracts between groups or sessions using AlphaSim. Voxelwise significance was determined at $p<0.001$. Subsequently, cluster-based significance was determined at $p<0.05$ (including $>25$ contiguous significant voxels; smoothness estimated as $4.5,4.8$, and $6.0 \mathrm{~mm}$ of full-width at half maximum Gaussian filter for the $x, y$, and $z$ directions, respectively).

Statistical analysis. Log-scaled video-game experience, task performance ( $80 \%$ threshold SOA) in each training session, and task performance (correct response ratio) in the pretraining and posttraining fMRI sessions were compared between VGPs and NVGPs using two-sample $t$ tests. A one-way repeated-measures ANOVA was used to compare task performance ( $80 \%$ threshold SOA) across behavioral training sessions (sessions 1-6). Two-way repeated-measures ANOVAs were used to evaluate the effects of VPL, effects of groups (VGPs, NVGPs), and its interactions. The effects of training were evaluated with various time points depending on variables: (1) across training sessions on threshold SOA in training (sessions 1-6); (2) across trials on task performances per 10 trials of $550 \mathrm{~ms} \mathrm{SOA}$ in training session 1 (from the first 10 to the last 10 trials, i.e., 12 time points for 120 trials); and (3) across fMRI sessions on task performance in fMRI, neuronal activity, and probabilistic connectivity (pretraining, posttraining). Two sample $t$ tests were performed to investigate the difference of behaviors, task performance in the fMRI sessions, task performance in the training sessions, neuronal activity, and probabilistic connectivity. Correlation analyses were performed to quantify the relations between video-game experience, task performance in the fMRI sessions, task performance in the training sessions, and neuronal activity and probabilistic connectivity in the significant clusters from the two-way repeated-measures ANOVAs. In all the correlation analyses, Grubb's outlier test was adopted to prevent inaccurate associations by an outlier (Grubb, 1969). Note that only subjects from Experiment 2 were included for the statistical analysis of the neuronal activity and task performance on fMRI, as indicated above. Although subjects were separated into two groups (i.e., Experiments 1 and 2) depending on SOA in fMRI sessions, all other aspects of the experimental design were identical. Thus, all subjects were included in the statistical analysis for video-game behaviors, task performance during training, and probabilistic connectivity, 
Table 1. Demographic and video-game-playing characteristics of VGPs and NVGPs

\begin{tabular}{lcccc}
\hline & $\begin{array}{l}\text { All subjects } \\
(n=31)\end{array}$ & $\begin{array}{l}\text { VGPs } \\
(n=16)\end{array}$ & $\begin{array}{l}\text { NVGPs } \\
(n=15)\end{array}$ & $p$ \\
\hline Age (years) & $29.0 \pm 4.1$ & $29.7 \pm 4.2$ & $28.3 \pm 4.1$ & 0.37 \\
Education (years) & $15.8 \pm 0.9$ & $15.8 \pm 0.9$ & $15.9 \pm 0.8$ & 0.86 \\
Game experience* (not scaled) & $3223 \pm 5246$ & $6100 \pm 6063$ & $154 \pm 189$ & $<0.001$ \\
$\begin{array}{l}\text { Game experience* (log-scaled) } \\
\text { Habitual game play (hours }\end{array}$ & $5.9 \pm 3.2$ & $8.3 \pm 0.9$ & $3.3 \pm 2.6$ & $<0.001$ \\
$\quad$ per week) & $4.2 \pm 5.4$ & $8.0 \pm 5.2$ & $0.2 \pm 0.5$ & $<0.001$ \\
Married & $7(23 \%)$ & $5(31.3 \%)$ & $2(13.3 \%)$ & 0.23 \\
\hline
\end{tabular}

*Game experience is the number of RTS game plays.

Data are mean \pm SD or number (column \%).

except correlation analysis with neuronal activity and task performance in fMRI sessions.

\section{Results}

\section{Subject characteristics}

Thirty-one healthy normal subjects (all males) were recruited for this study: 16 VGPs and 15 NVGPs. All subjects led ordinary lives in terms of family, social, and economic activities. The mean \pm SD age of enrolled subjects was $29.0 \pm 4.1$ years, with no difference between VGPs and NVGPs (Table 1). Of 16 VGPs, 12 played RTS video games at least $5 \mathrm{~h} /$ week, and another four played at least $4 \mathrm{~h}$ /week. Video-game experience (i.e., the number of RTS game plays) and habitual game play (play hours per week) were greater in VGPs than in NVGPs (Table 1). Log-scaled video-game experience was assumed to have a normal distribution and was used in all subsequent analyses (normalized kurtosis $K=4.47$ from non-scaled population and $K=-0.48$ from log-scaled population).

\section{Task performance during training}

All subjects $(n=31)$ successfully completed six training sessions for the TDT. Performance during each training session was quantified using the $80 \%$ threshold for the SOA. There was a significant effect of training session on the $80 \%$ threshold for SOA $\left(F_{(5,150)}=13.3, p<0.001\right.$; Fig. $\left.1 a\right)$. From the two-way repeatedmeasures ANOVA on threshold SOA, there were significant training effect across sessions $\left(F_{(5,145)}=14.98, p<0.001\right)$ and interaction between sessions and groups $\left(F_{(5,145)}=4.90, p<\right.$ $0.001)$ but no effects of group $\left(F_{(1,145)}=2.91, p=0.098\right)$. SOA threshold was lower (i.e., performance was better) at the end of training than at the beginning of training. In the first training session, SOA threshold was lower for VGPs than for NVGPs ( $p=$ $0.009)$. However, the gap between the two groups became insignificant $(p>0.05)$ as training proceeded further (Fig. 1a). For additional analysis of initial performance, we took the average of each 10 trials of the first block of the first training session for the two groups and compared the mean performance between the two groups. From the two-way repeated-measures ANOVA on correct response (percentage) for initial trials with $550 \mathrm{~ms}$ SOA in session 1, there were significant training effect $\left(F_{(11,319)}=10.2\right.$, $p<0.001)$ and moderate group effect $\left(F_{(1,319)}=4.04, p=0.054\right)$ but no interaction $\left(F_{(11,319)}=0.46, p=0.93\right)$. However, there was no difference in the performance for the first 10 trials between the two groups. Then the performance difference emerged quickly in the course of initial training (Fig. 1b).

\section{Task performance in $\mathrm{fMRI}$ session}

Subjects were split into two groups. The two groups performed the same experiment but differed on the SOA used for the TDT in the pretraining and posttraining fMRI sessions. Seventeen sub- jects ( $n=9$ VGPs and $n=8$ NVGPs) participated in Experiment 1 and performed the TDT with an SOA of $100 \mathrm{~ms}$ during the pretraining and posttraining fMRI sessions. Fourteen subjects ( $n=7$ VGPs and $n=7$ NVGPs) participated in Experiment 2 and performed the TDT with an SOA of $150 \mathrm{~ms}$ during the pretraining and posttraining fMRI sessions. All other aspects of the experiments were identical. From the two-way repeated-measures ANOVA on correct response ratio in $\mathrm{fMRI}$ (session $\times$ group) in Experiment 1, there was no improvement from the pretraining to the posttraining fMRI session, no group difference, and no significant interaction (see Materials and Methods, TDT during fMRI). In contrast, in Experiment 2, the correct response ratio increased from before to after training $(p<0.001)$. Specifically, performance increase was observed in both trained $(p=0.0073$ in VGPs, $p=0.034$ in NVGPs) and untrained ( $p=0.0029$ in VGPs, $p=0.014$ in NVGPs) quadrants (Fig. 2). There were no significant differences between groups (VGPs and NVGPs) or between visual-field conditions (stimulus in the trained quadrant and stimulus in the untrained quadrant) on the correct response ratio in the pretraining or posttraining sessions in Experiment 2 (Fig. 2).

\section{Neuronal activity during the TDT}

fMRI analysis for neuronal activity was performed in Experiment 2 only ( $n=7$ VGPs and $n=7$ NVGPs) because of the reason mentioned above. fMRI was conducted to investigate neuronal activity during the TDT before and after training. Neuronal activity in the right inferior frontal gyrus (IFG), a part of the middle frontal gyrus, and the ACC was greater in VGPs than in NVGPs both before and after training (i.e., main effect of group; Fig. 3a). Task-positive activations in the right IFG were observed both before and after training in VGPs but not in NVGPs. Taskpositive activations in the ACC were evident for both VGPs and NVGPs, but the level of activation was higher with VGPs than with NVGPs both before and after training. There was no cluster that showed significantly greater neuronal activity in NVGPs than in VGPs. In both VGPs and NVGPs, neuronal activity in the right caudate and left putamen and the caudate was lower after training than before training (i.e., main effect of session; Fig. $3 b$ ). Both regions responded to the TDT with positive activation at the pretraining session but did not show significant task-induced activity at the posttraining session. There was no cluster that showed significantly greater neuronal activity after training than before training. There was no significant cluster in neuronal activity by the interaction analysis between the groups and sessions.

\section{Structural characteristics of white-matter tracts}

Probabilistic tractography was performed in all subjects $(n=31)$ to investigate white-matter connectivity from the visual cortex to other brain areas (Behrens et al., 2007). Probabilistic tracts from ROIs in the visual cortex were reconstructed successfully: the inferior occipitofrontal fasciculus, which projects to ventral regions of the frontal lobe passing through the anterior part of the external capsule, the inferior longitudinal fasciculus, which projects to the temporal lobe, and the cingulum for the medial surface (Fig. 4a; Catani and Thiebaut de Schotten, 2008). A greater level of probabilistic connectivity between with the visual cortex and the right anterior part of the external capsule was observed in VGPs than in NVGPs $(p<0.001$; Fig. $4 b, c)$, whereas none of the areas showed a greater level of probabilistic connectivity in NVGPs than in VGPs. There were no significant clusters between the sessions and interaction. 

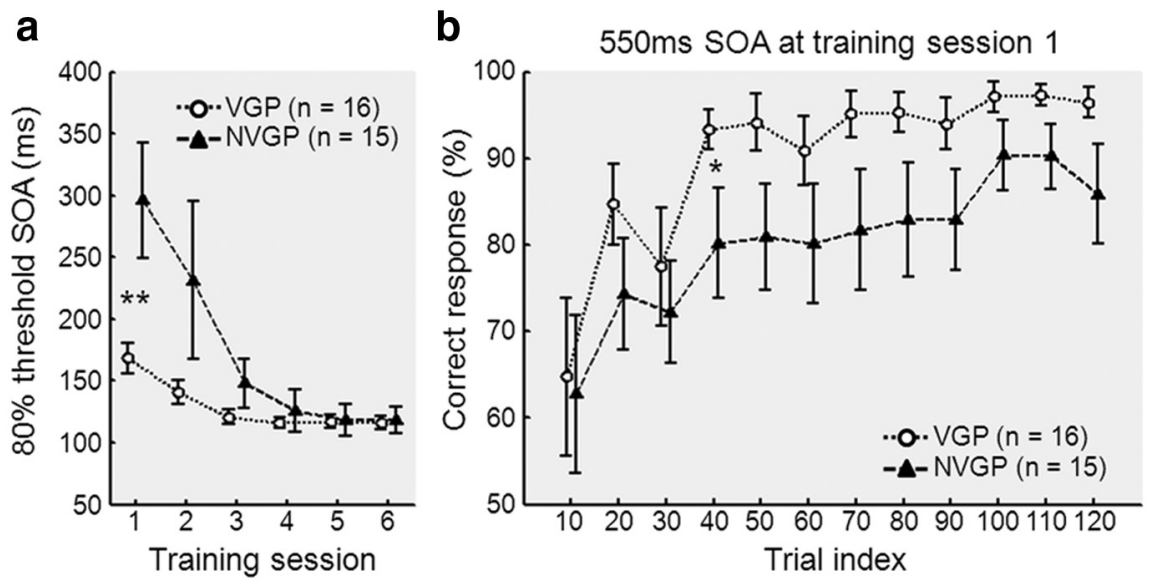

Figure 1. Task performance on the TDT. $\boldsymbol{a}$, The average \pm SE $80 \%$ threshold SOA of VGPs $(n=16)$ and NVGPs $(n=15)$ in each of the six training sessions were plotted. A lower threshold SOA indicates better performance. $\boldsymbol{b}$, The mean percentage of correct response with VGPs $(n=16)$ and NVGPs $(n=15)$ in each 10 trials of fixed SOA of $550 \mathrm{~ms}$ at training session 1 . Greater percentage indicates better performance. ${ }^{*} p<0.05,{ }^{* *} p<0.01$.

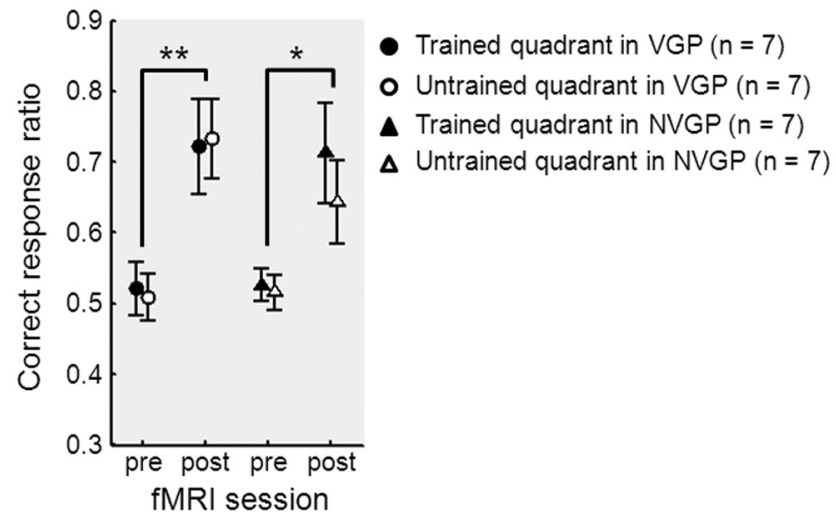

Figure 2. Task performance on the TDT in the fMRI session. The mean $\pm \mathrm{SE}$ correct response ratio for VGPs $(n=7)$ and NVGPs $(n=7)$ in the fMRI session for the pretraining and posttraining groups of Experiment 2 (SOA of $150 \mathrm{~ms}$ ). A greater correct response ratio indicates better performance. ${ }^{*} p<0.05,{ }^{* *} p<0.01$.

\section{Correlation between baseline characteristics and task performance}

Correlation analysis was conducted to investigate the relation between baseline characteristics and TDT performance in all subjects $(n=31$; Fig. 5). At training session 1, threshold SOA was correlated negatively with video-game experience $(p=0.004)$ and habitual game plays $(p=0.03)$. At training session $2(n=30$ after excluding an outlier of NVGPs), threshold SOA was correlated negatively with log-scaled video-game experience $(p=$ 0.02 ). These results indicate that performance was better in subjects with more video-game experience and a higher level of habitual game play in the initial training period. In the fMRI session $(n=$ 14, 7 VGPs and 7 NVGPs), there was no significant correlation between task performance and log-scaled video-game experience or between task performance and habitual video-game play.

Correlation of neuronal activity during TDT with video-game experience and task performance

Correlation analysis of fMRI with game experience and task performance was conducted only with data from Experiment $2(n=$ 7 VGPs and $n=7$ NVGPs). Log-scaled video-game experience was significantly positively correlated with neuronal activities in the right IFG ( $p=0.02$ and $p=0.005$ before and after training),
ACC ( $p=0.03$ and $p=0.03$ before and after training), left putamen ( $p=0.03$ after training), and right caudate ( $p=0.02$ after training) but no significant associations with the left putamen and right caudate before training. Habitual video-game play was also significantly positively correlated with neuronal activities in the right IFG $(p=0.01$ and $p<0.001$ before and after training) and ACC ( $p=0.02$ and $p<$ 0.001 before and after training). Conversely, neuronal activities in the left putamen and right caudate were not correlated significantly with habitual video-game play either before or after training (left putamen, $p=0.24$ and $p=$ 0.23 before and after training; right caudate, $p=0.24$ and $p=0.06$ before and after training).

In the pretraining and posttraining fMRI sessions, there was no significant correlation between neuronal activity and threshold SOA. There was no significant correlation between neuronal activities in the ROIs and task performance in either the pretraining or posttraining fMRI session.

\section{Correlation of white-matter connectivity with video-game experience and task performance}

The probabilistic connectivity level in the right external capsule (defined from group comparison in the exploratory analysis with seed ROI in the visual cortex) was significantly positively correlated with video-game experience $(n=31 ; p=0.003$ and $p=$ 0.005 before and after training, respectively) but was not significantly correlated with habitual video-game play $(n=31)$ and task performances in both training $(n=31)$ and fMRI $(n=14$, Experiment 2 group) sessions.

\section{Structural and functional correlates}

Correlation analysis of fMRI with probabilistic connectivity was conducted with data from Experiment $2(n=14,7$ VGPs and 7 NVGPs). The probabilistic connectivity of the right external capsule with the visual cortex was significantly positively correlated with the neuronal activity of the right IFG $(p=0.0002)$, ACC $(p=0.0008)$, and left putamen $(p=0.02)$ in the pretraining fMRI session. However, no significant correlation between structural connectivity and neuronal activity was observed after training.

\section{Discussion}

In this study, we investigated the effects of RTS video-game experience on VPL and aimed to elucidate the neural mechanisms that underlie differences in VPL between RTS VGPs and NVGPs and to test whether improved higher-order cognitive skills by RTS experience are involved in the development of VPL. We found that VGPs had better performance on the TDT in the early phase of training. Although the performance difference between the two groups was not observed in the first 10 trials, after the phase, it started being seen abruptly. Neuronal activity in the right IFG and ACC during TDT was greater in VGPs than in NVGPs. Consistent with this result, the white-matter connectivity of the right external capsule with the visual cortex, i.e., the pathway between the visual cortex and inferior frontal lobe, had stronger probabilistic connections in VGPs than in NVGPs. 
a Group effects (VGP > NVGP)
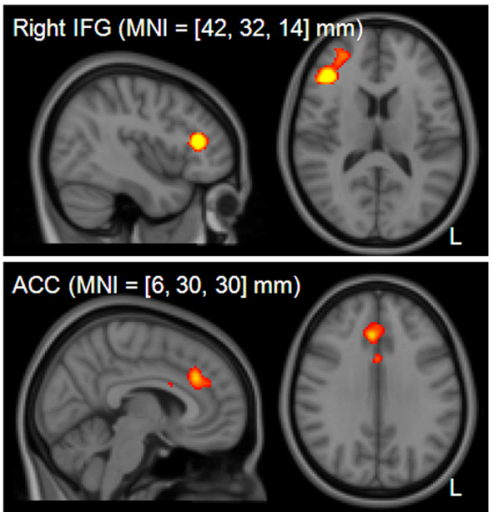
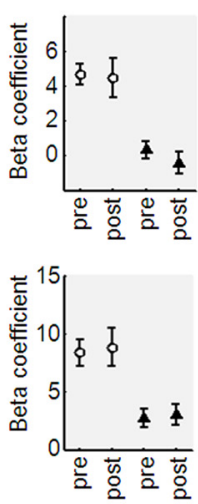

b Training effects (pre > post)
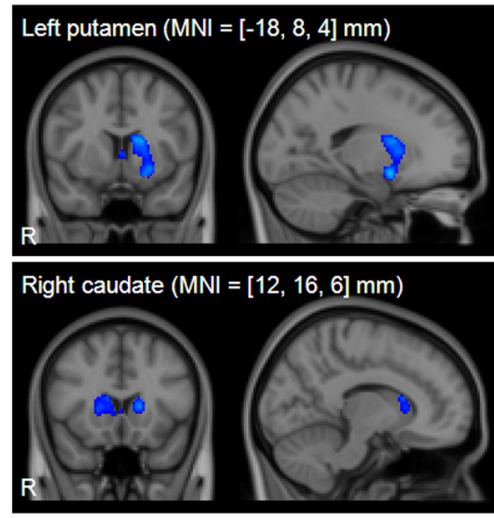
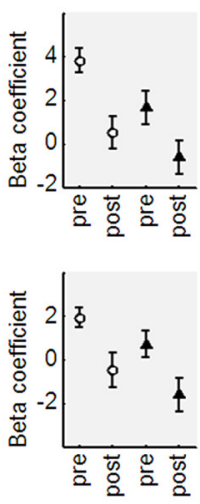

$p=10^{-3}$

- Video game player $(n=7)$

-Non-video game player $(n=7)$

Figure 3. Main effects of group and training on neuronal activity during the TDT. $\boldsymbol{a}$, Main effects from group comparisons. The right IFG (top) and ACC (bottom) had significant clusters. The red-to-yellow color scale represents the level of significance at each voxel. $\beta$ coefficients were averaged within each cluster, and the average \pm SE $\beta$ coefficients for VGPs ( $n=7$ ) and NVGPs $(n=$ 7) in Experiment 2 are shown on the right. $\boldsymbol{b}$, Main effects from session comparisons. The left putamen and caudate (top) and the right caudate (bottom) had significant clusters. The blue-to-light blue color scale represents the level of significance at each voxel. $\beta$ coefficients were averaged within a cluster, and the average \pm SE $\beta$ coefficients for VGPS ( $n=7)$ and NVGPs $(n=7)$ in Experiment 2 are shown on the right.

a

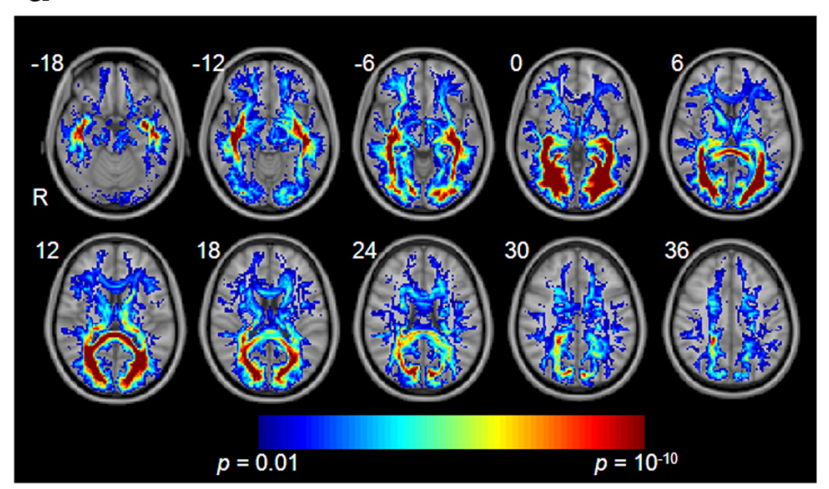

b

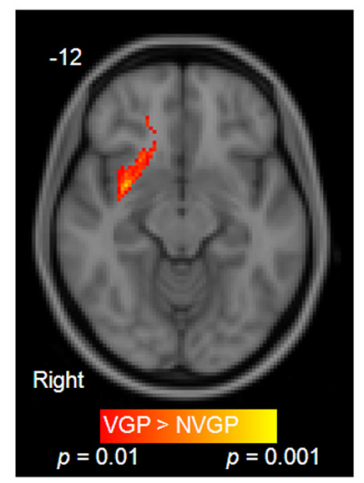

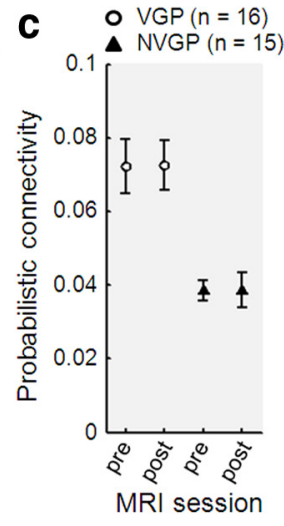

Figure 4. Reconstructed probabilistic pathways from the ROl in the visual cortex. $\boldsymbol{a}$, The inferior occipitofrontal fasciculus, inferior longitudinal fasciculus, and cingulum pathways are shown as a result of a one-sample $t$ test applied to the data from all the subjects at the pretraining MRI session $(n=31)$. The blue-to-red color scale represents a statistical significance of probabilistic connectivity. $\boldsymbol{b}$, A greater level of probabilistic connectivity from the visual cortex was observed along the anterior part of the right external capsule in VGPs $(n=16)$ than in NVGPs $(n=15)$, whereas no area showed a greater level of probabilistic connectivity in NVGPs than in VGPs. The red-to-yellow color scale represents a statistical significance of group differences. MNI coordinates ( $z$-axis) are noted on the top left of each slice. c, The mean \pm SE probabilistic connectivity in the significant cluster for VGPs $(n=16)$ and NVGPs $(n=15)$ in the pre-TDT and post-TDT training MRI sessions.

These results are in accord with the hypothesis that RTS experience improves cognitive abilities associated with functional and anatomical changes in brain areas higher than the early visual cortex and that these higher-order cognitive abilities facilitate VPL particularly in the early phase of training.

We have also found that the performance was improved not only in the trained location but also in the untrained location. As discussed in Introduction, a large literature has shown that VPL is location specific (Poggio et al., 1992; Karni and Sagi, 1993; Crist et al., 1997; Watanabe et al., 2002; Yotsumoto et al., 2008, 2009). However, recently it has been found that, in some conditions, VPL is not feature/location specific (Green and Bavelier, 2003, 2012; Xiao et al., 2008; Green et al., 2010; Oei and Patterson, 2013; Wu and Spence, 2013). Harris et al. (2012) found that the location specificity in VPL of TDT was totally abolished, and complete generalization occurs if a procedure to reduce sensitivity was applied to the target location in TDT. Based on this finding, Harris et al. (2012) and Shibata et al. (2014) built the model in which VPL results from at least one of two types of plasticity: (1)

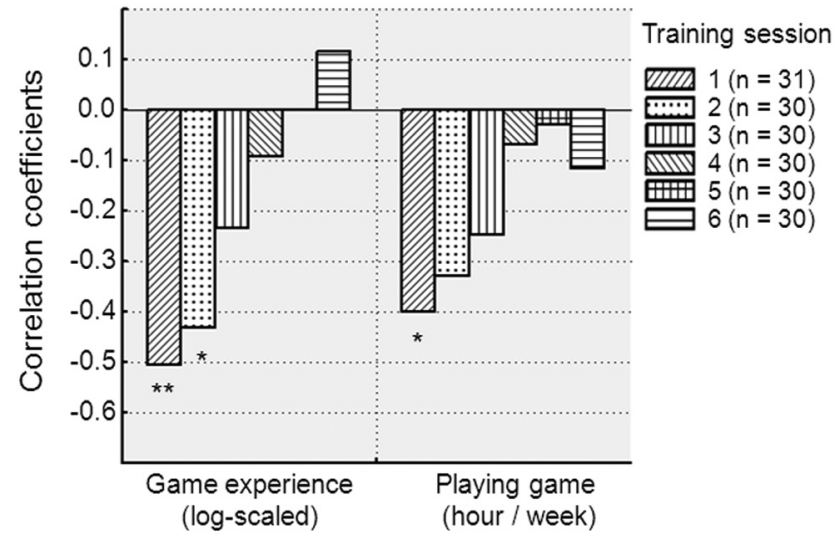

Figure 5. Correlation coefficients between baseline characteristics (log-scaled video-game playing experience and playing game hours per week) and the mean $80 \%$ threshold $50 \mathrm{~A}$ in each training session ( $n=31$ for training session 1 and $n=30$ for other sessions after excluding an outlier in threshold SOA). ${ }^{*} p<0.05,{ }^{* *} p<0.01$. 
feature-based plasticity that occurs in the early visual cortex in a location/feature-specific manner; and (2) task-based plasticity, which involves higher cognitive areas and is not location/feature specific. The current result of no location specificity in VPL of TDT is in accord with the hypothesis that VPL of TDT results from changes in higher-order cognitive regions.

We believe that differences in neural plasticity between VGPs and NVGPs may explain the difference in TDT performance. White-matter connectivity from the visual area to the frontal cortex (i.e., the inferior occipitofrontal fasciculus) in the right hemisphere was more developed in VGPs than in NVGPs. These results suggest that structural plasticity had occurred by longterm video-game experience. In accordance with these structural data, neuronal activity in the right IFG and the ACC during TDT was greater in VGPs than in NVGPs, and these differences remained even after training. Previously, it has been reported that the right IFG and the ACC were activated for unexpected stimuli (Sharp et al., 2010) and for cognitive-demanding tasks (Duncan et al., 2000; Nee et al., 2007). However, note that our study was based on the correlation analysis; therefore, it cannot be determined whether the anatomical and functional differences between the VGP and NVGP groups were the cause or the result of long-term video-game experience. For instance, gamers might be blessed with the greater level of white-matter connectivity from the visual area to the frontal cortex that allowed them to excel and persist in the video-game playing.

Interestingly, as training progressed, the performance gap between VGPs and NVGPs reduced, and performance level reached a plateau in both groups. In support of this, a strong correlation between video-game experience and TDT performance was observed in the early phase of training but weakened in the later phase of training. These results indicate that the learning effect became more prominent than the video-game experience effect as VPL well progresses.

The neural plasticity associated with long-term video-game experience may be affected by the genre of video game because of genre-dependent functional requirements. VGPs in the present study had played primarily RTS games (i.e., StarCraft or WarCraft) that require real-time coordination of complex cognitive activities of planning and strategizing against an enemy army. This is reflected with the results of MRI experiments indicating that structural and functional correlates in frontal areas and connectivity between visual and frontal areas were more developed in VGPs than in NVGPs.

Conversely, although action video games involve high-order cognitive areas (Kühn and Gallinat, 2014; Gong et al., 2015), the role of the posterior parietal area, which is associated with visual attention, is highly pronounced. Thus, the positive influence of the RTS video-game experience on VPL in the present study suggests that particularly high-ordered cognitive skills are involved in VPL.

The caudate and putamen in both VGPs and NVGPs showed task-related positive activation before training but not after training. These results suggest that the caudate and putamen may play an important role in VPL, particularly in the early phase of training. The basal ganglia, including the caudate and the putamen, may function as an independent memory system in learning cases (Poldrack and Packard, 2003). In rats, the majority of caudateputamen responses to stimulation of the entorhinal cortex were inhibitory (Finch et al., 1995). In human brains, the caudate and putamen showed an increase in BOLD signal during cognitive skill acquisition (Poldrack et al., 1999), motor sequence learning (Reithler et al., 2010), and phonetic learning (Tricomi et al.,
2006). This result is also consistent with the model that the basal ganglia is involved in learning until cortical association is established (Hélie et al., 2015). The activation of these brain regions for a novel visual task and the deactivation when the visual task was no longer novel in the present study may provide additional evidence for interaction of the basal ganglia with learning/memory systems.

Results of the present study suggest that VPL is associated with higher-order cognitive areas. However, this does not indicate invariably that higher-order cognitive areas are the only regions in which VPL occurs. A number of studies have found changes in the early visual cortex associated with VPL (Schoups et al., 2001; Furmanski et al., 2004; Yotsumoto et al., 2008, 2009; Shibata et al., 2011). As mentioned in Introduction, it has been suggested that VPL results from two types of plasticity: (1) feature-based plasticity; and (2) task-based plasticity. The feature-based plasticity occurs in early visual areas to improve a representation of the trained feature, whereas the task-based plasticity occurs in more cognitive areas to improve tasks (Shibata et al., 2014; Watanabe and Sasaki, 2015). If true, the results of the present study are in accord with the task-based plasticity.

In the present study, we examined how long-term video-game experience and habitual game playing influenced visual perceptual abilities and VPL. Changes in structural connectivity and neural plasticity attributable to long-term video-game experience may underlie better perceptual learning of VGPs in the early phase of training on a novel task. These results have implications for our understanding of the neural mechanisms underlying interindividual variations in higher-order cognitive abilities and VPL.

\section{References}

Basak C, Boot WR, Voss MW, Kramer AF (2008) Can training in a real-time strategy video game attenuate cognitive decline in older adults? Psychol Aging 23:765-777. CrossRef Medline

Basak C, Voss MW, Erickson KI, Boot WR, Kramer AF (2011) Regional differences in brain volume predict the acquisition of skill in a complex real-time strategy videogame. Brain Cogn 76:407-414. CrossRef Medline

Behrens TE, Woolrich MW, Jenkinson M, Johansen-Berg H, Nunes RG, Clare S, Matthews PM, Brady JM, Smith SM (2003) Characterization and propagation of uncertainty in diffusion-weighted MR imaging. Magn Reson Med 50:1077-1088. CrossRef Medline

Behrens TE, Berg HJ, Jbabdi S, Rushworth MF, Woolrich MW (2007) Probabilistic diffusion tractography with multiple fibre orientations: what can we gain? Neuroimage 34:144-155. CrossRef Medline

Bejjanki VR, Zhang R, Li R, Pouget A, Green CS, Lu ZL, Bavelier D (2014) Action video game play facilitates the development of better perceptual templates. Proc Natl Acad Sci U S A 111:16961-16966. CrossRef Medline

Beste C, Dinse HR (2013) Learning without training. Curr Biol 23:R489R499. CrossRef Medline

Cardoso-Leite P, Bavelier D (2014) Video game play, attention, and learning: how to shape the development of attention and influence learning? Curr Opin Neurol 27:185-191. CrossRef Medline

Catani M, Thiebaut de Schotten M (2008) A diffusion tensor imaging tractography atlas for virtual in vivo dissections. Cortex 44:1105-1132. CrossRef Medline

Crist RE, Kapadia MK, Westheimer G, Gilbert CD (1997) Perceptual learning of spatial localization: specificity for orientation, position, and context. J Neurophysiol 78:2889-2894. Medline

Dale AM (1999) Optimal experimental design for event-related fMRI. Hum Brain Mapp 8:109-114. CrossRef Medline

Dale AM, Greve DN, Burock MA (1999) Optimal stimulus sequences for event-realted fMRI. Fifth International Conference on Functional Mapping of the Human Brain, Duesseldorf, Germany, June.

Desikan RS, Ségonne F, Fischl B, Quinn BT, Dickerson BC, Blacker D, Buckner RL, Dale AM, Maguire RP, Hyman BT, Albert MS, Killiany RJ (2006) An automated labeling system for subdividing the human cerebral cortex 
on MRI scans into gyral based regions of interest. Neuroimage 31:968980. CrossRef Medline

Deveau J, Ozer DJ, Seitz AR (2014) Improved vision and on-field performance in baseball through perceptual learning. Curr Biol 24:R146-R147. CrossRef Medline

Dobrowolski P, Hanusz K, Sobczyk B, Skorko M, Wiatrow A (2015) Cognitive enhancement in video game players: the role of video game genre. Comput Hum Behav 44:59-63. CrossRef

Duncan J, Owen AM (2000) Common regions of the human frontal lobe recruited by diverse cognitive demands. Trends Neurosci 23:475-483. CrossRef Medline

Finch DM, Gigg J, Tan AM, Kosoyan OP (1995) Neurophysiology and neuropharmacology of projections from entorhinal cortex to striatum in the rat. Brain Res 670:233-247. CrossRef Medline

Fischl B, van der Kouwe A, Destrieux C, Halgren E, Ségonne F, Salat DH, Busa E, Seidman LJ, Goldstein J, Kennedy D, Caviness V, Makris N, Rosen B, Dale AM (2004) Automatically parcellating the human cerebral cortex. Cereb Cortex 14:11-22. CrossRef Medline

Friston KJ, Fletcher P, Josephs O, Holmes A, Rugg MD, Turner R (1998) Event-related fMRI: characterizing differential responses. Neuroimage 7:30-40. CrossRef Medline

Furmanski CS, Schluppeck D, Engel SA (2004) Learning strengthens the response of primary visual cortex to simple patterns. Curr Biol 14:573578. CrossRef Medline

Glass BD, Maddox WT, Love BC (2013) Real-time strategy game training: emergence of a cognitive flexibility trait. PLoS One 8:e70350. CrossRef Medline

Gong D, He H, Liu D, Ma W, Dong L, Luo C, Yao D (2015) Enhanced functional connectivity and increased gray matter volume of insula related to action video game playing. Sci Rep 5:9763. CrossRef Medline

Green CS, Bavelier D (2003) Action video game modifies visual selective attention. Nature 423:534-537. CrossRef Medline

Green CS, Bavelier D (2012) Learning, attentional control, and action video games. Curr Biol 22:R197-R206. CrossRef Medline

Green CS, Pouget A, Bavelier D (2010) Improved probabilistic inference as a general learning mechanism with action video games. Curr Biol 20: 1573-1579. CrossRef Medline

Green CS, Sugarman MA, Medford K, Klobusicky E, Bavelier D (2012) The effect of action video game experience on task-switching. Comput Hum Behav 28:984-994. CrossRef

Grubb FE (1969) Procedures for detecting outlying observations in samples. Technometrics 11:1-21. CrossRef

Harris H, Gliksberg M, Sagi D (2012) Generalized perceptual learning in the absence of sensory adaptation. Curr Biol 22:1813-1817. CrossRef Medline

Hélie S, Ell SW, Ashby FG (2015) Learning robust cortico-cortical associations with the basal ganglia: an integrative review. Cortex 64:123-135. CrossRef Medline

Hussain Z, Webb BS, Astle AT, McGraw PV (2012) Perceptual learning reduces crowding in amblyopia and in the normal periphery. J Neurosci 32:474-480. CrossRef Medline

Huxlin KR, Martin T, Kelly K, Riley M, Friedman DI, Burgin WS, Hayhoe M (2009) Perceptual relearning of complex visual motion after V1 damage in humans. J Neurosci 29:3981-3991. CrossRef Medline

Jenkinson M, Beckmann CF, Behrens TE, Woolrich MW, Smith SM (2012) FSL. Neuroimage 62:782-790. CrossRef Medline

Karni A, Sagi D (1991) Where practice makes perfect in texture discrimination: evidence for primary visual cortex plasticity. Proc Natl Acad Sci U S A 88:4966-4970. CrossRef Medline

Karni A, Sagi D (1993) The time course of learning a visual skill. Nature 365:250-252. CrossRef Medline

Kühn S, Gallinat J (2014) Amount of lifetime video gaming is positively associated with entorhinal, hippocampal and occipital volume. Mol Psychiatry 19:842-847. CrossRef Medline

Nee DE, Wager TD, Jonides J (2007) Interference resolution: insights from a meta-analysis of neuroimaging tasks. Cogn Affect Behav Neurosci 7:1-17. CrossRef Medline

Oei AC, Patterson MD (2013) Enhancing cognition with video games: a multiple game training study. PLoS One 8:e58546. CrossRef Medline
Poggio T, Fahle M, Edelman S (1992) Fast perceptual learning in visual hyperacuity. Science 256:1018-1021. CrossRef Medline

Polat U (2009) Making perceptual learning practical to improve visual functions. Vision Res 49:2566-2573. CrossRef Medline

Poldrack RA, Packard MG (2003) Competition among multiple memory systems: converging evidence from animal and human brain studies. Neuropsychologia 41:245-251. CrossRef Medline

Poldrack RA, Prabhakaran V, Seger CA, Gabrieli JD (1999) Striatal activation during acquisition of a cognitive skill. Neuropsychology 13:564-574. CrossRef Medline

Power JD, Barnes KA, Snyder AZ, Schlaggar BL, Petersen SE (2012) Spurious but systematic correlations in functional connectivity MRI networks arise from subject motion. Neuroimage 59:2142-2154. CrossRef Medline

Reithler J, van Mier HI, Goebel R (2010) Continuous motor sequence learning: cortical efficiency gains accompanied by striatal functional reorganization. Neuroimage 52:263-276. CrossRef Medline

Sagi D, Tanne D (1994) Perceptual learning: learning to see. Curr Opin Neurobiol 4:195-199. CrossRef Medline

Sasaki Y, Nanez JE, Watanabe T (2010) Advances in visual perceptual learning and plasticity. Nat Rev Neurosci 11:53-60. CrossRef Medline

Schoups A, Vogels R, Qian N, Orban G (2001) Practising orientation identification improves orientation coding in V1 neurons. Nature 412:549553. CrossRef Medline

Sharp DJ, Bonnelle V, De Boissezon X, Beckmann CF, James SG, Patel MC, Mehta MA (2010) Distinct frontal systems for response inhibition, attentional capture, and error processing. Proc Natl Acad Sci U S A 107: 6106-6111. CrossRef Medline

Shibata K, Watanabe T, Sasaki Y, Kawato M (2011) Perceptual learning incepted by decoded fMRI neurofeedback without stimulus presentation. Science 334:1413-1415. CrossRef Medline

Shibata K, Sagi D, Watanabe T (2014) Two-stage model in perceptual learning: toward a unified theory. Ann N Y Acad Sci 1316:18-28. CrossRef Medline

Song XW, Dong ZY, Long XY, Li SF, Zuo XN, Zhu CZ, He Y, Yan CG, Zang YF (2011) REST: a toolkit for resting-state functional magnetic resonance imaging data processing. PLoS One 6:e25031. CrossRef Medline

Strobach T, Frensch PA, Schubert T (2012) Video game practice optimizes executive control skills in dual-task and task switching situations. Acta Psychol (Amst) 140:13-24. CrossRef Medline

Tricomi E, Delgado MR, McCandliss BD, McClelland JL, Fiez JA (2006) Performance feedback drives caudate activation in a phonological learning task. J Cogn Neurosci 18:1029-1043. CrossRef Medline

Watanabe T, Sasaki Y (2015) Perceptual learning: toward a comprehensive theory. Annu Rev Psychol 66:197-221. CrossRef Medline

Watanabe T, Náñez JE Sr, Koyama S, Mukai I, Liederman J, Sasaki Y (2002) Greater plasticity in lower-level than higher-level visual motion processing in a passive perceptual learning task. Nat Neurosci 5:1003-1009. CrossRef Medline

Wu S, Spence I (2013) Playing shooter and driving videogames improves top-down guidance in visual search. Atten Percept Psychophys 75:673686. CrossRef Medline

Xi J, Jia WL, Feng LX, Lu ZL, Huang CB (2014) Perceptual learning improves stereoacuity in amblyopia. Invest Ophthalmol Vis Sci 55:23842391. CrossRef Medline

Xiao LQ, Zhang JY, Wang R, Klein SA, Levi DM, Yu C (2008) Complete transfer of perceptual learning across retinal locations enabled by double training. Curr Biol 18:1922-1926. CrossRef Medline

Yotsumoto Y, Watanabe T, Sasaki Y (2008) Different dynamics of performance and brain activation in the time course of perceptual learning. Neuron 57:827-833. CrossRef Medline

Yotsumoto Y, Sasaki Y, Chan P, Vasios CE, Bonmassar G, Ito N, Náñez JE Sr, Shimojo S, Watanabe T (2009) Location-specific cortical activation changes during sleep after training for perceptual learning. Curr Biol 19:1278-1282. CrossRef Medline

Zhang JY, Cong LJ, Klein SA, Levi DM, Yu C (2014) Perceptual learning improves adult amblyopic vision through rule-based cognitive compensation. Invest Ophthalmol Vis Sci 55:2020-2030. CrossRef Medline 